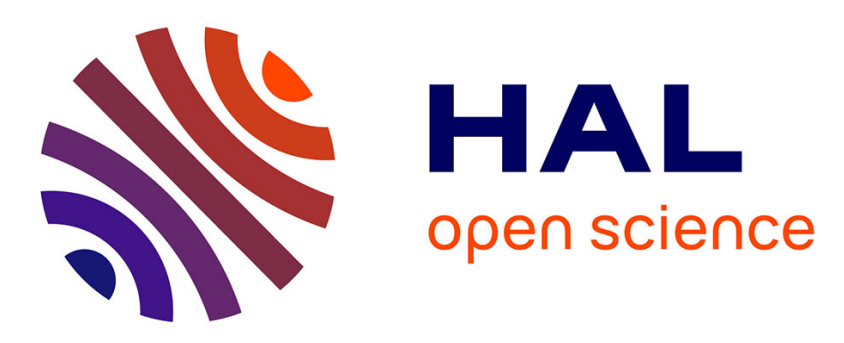

\title{
A Brillouin light scattering study of the $\lambda$ transition in liquid sulphur
}

Filippo Scarponi, Daniele Fioretto, Laura Crapanzano, Giulio Monaco

\section{To cite this version:}

Filippo Scarponi, Daniele Fioretto, Laura Crapanzano, Giulio Monaco. A Brillouin light scattering study of the $\lambda$ transition in liquid sulphur. Philosophical Magazine, 2007, 87 (3-5), pp.673-679. 10.1080/14786430601032402 . hal-00513795

\section{HAL Id: hal-00513795 \\ https://hal.science/hal-00513795}

Submitted on 1 Sep 2010

HAL is a multi-disciplinary open access archive for the deposit and dissemination of scientific research documents, whether they are published or not. The documents may come from teaching and research institutions in France or abroad, or from public or private research centers.
L'archive ouverte pluridisciplinaire HAL, est destinée au dépôt et à la diffusion de documents scientifiques de niveau recherche, publiés ou non, émanant des établissements d'enseignement et de recherche français ou étrangers, des laboratoires publics ou privés. 


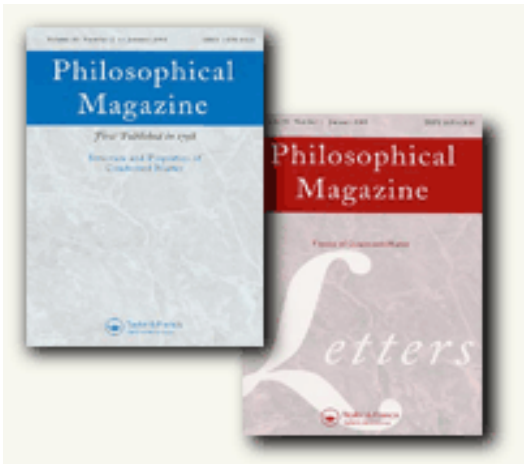

\section{A Brillouin light scattering study of the $\boldsymbol{\lambda}$ transition in liquid sulphur}

\begin{tabular}{|c|c|}
\hline Journal: & Philosophical Magazine \& Philosophical Magazine Letters \\
\hline Manuscript ID: & TPHM-06-May-0165.R1 \\
\hline Journal Selection: & Philosophical Magazine \\
\hline $\begin{array}{r}\text { Date Submitted by the } \\
\text { Author: }\end{array}$ & 19-Sep-2006 \\
\hline Complete List of Authors: & $\begin{array}{l}\text { Scarponi, Filippo; Università di Perugia, Fisica } \\
\text { Fioretto, Daniele; Università di Perugia, Fisica } \\
\text { Crapanzano, Laura; ESRF } \\
\text { Monaco, Giulio; ESRF }\end{array}$ \\
\hline Keywords: & optical spectroscopy, polymerization \\
\hline Keywords (user supplied): & lamdba transition, Brillouin Ligth Scattering, living polymerization \\
\hline
\end{tabular}

\section{今) ScholaroNE \\ Manuscript Central}




\title{
A Brillouin light scattering study of the $\lambda$ transition in liquid sulphur
}

\author{
F. SCARPONI ${ }^{\dagger *}$, D. FIORETTO ${ }^{\dagger}$, L. CRAPANZANO ${ }^{\ddagger}$, G. MONACO \\ †Dipartimento di fisica, Università di Perugia, Via Pascoli, I-06102 Perugia, Italy. \\ “INFM CRS-SOFT c/o Università di Roma "La Sapienza”, P. A. Moro 2, I-00185 Roma, Italy. \\ ${ }^{\ddagger}$ European Synchrotron Radiation Facility, B.P. 220, F-38043 Grenoble Cedex, France.
}

The dynamics of liquid sulphur has been investigated in the temperature region corresponding to the so-called $\lambda$ transition by means of Brillouin Light Scattering. Results of this work, together with ultrasonic spectroscopy and inelastic X-ray scattering results in literature, indicate that the main structural relaxation in slightly affected by the transition and suggest the dramatic increase of shear viscosity to be related to the onset of a low frequency additional relaxation. Such a feature is commonly found in rubber-like materials and can be related to the polymerization of sulphur molecules across the transition.

Keywords : Sulphur; Lambda transition; Brillouin light scattering; Living polymerization

*corresponding author :

Email: scarponi@fisica.unipg.it-Tel-Fax:+39075 5852767 


\section{Introduction}

Sulphur is one of the more common chemical elements on the earth, well known since the most ancient times due to its abundance (it is often found in large natural repositories near active volcanoes), its penetrating smell and its flammability. At ambient temperature and pressure sulphur is a pale yellow solid; it melts at about $393 \mathrm{~K}$ to form a low viscosity liquid and becomes vapour at 717 K. Starting from a temperature $T_{\lambda}$ of about $433 \mathrm{~K}$, liquid sulphur undergoes a complex chemical and physical transformation, commonly known as $\lambda$ transition.

The best known feature of the $\lambda$ transition is the enormous increase in shear viscosity [1] immediately above $\mathrm{T}_{\lambda}$, from values in the order of $10^{-2} \mathrm{~Pa} \cdot \mathrm{s}$ to a maximum, slightly lower than $10^{2}$ $\mathrm{Pa} \cdot \mathrm{s}$, at about $458 \mathrm{~K}$; at higher temperatures the viscosity decreases smoothly and reverts to low values over $600 \mathrm{~K}$. Remarkable modifications during the $\lambda$ transition concern also the specific heat [2], the index of refraction [3] and the optical absorption [4]. The density of liquid sulphur [5] and ultrasonic sound speed [6-9] have also been measured in the $\lambda$ transition region and appear to be comparatively less sensitive to the phenomenon.

The physical modifications described so far can all be related to the living polymerization [10] of sulphur molecules which takes place spontaneously in the $\lambda$ transition region. In the solid and in the ordinary liquid phase (below $\mathrm{T}_{\lambda}$ ) sulphur is composed by crown shaped $\mathrm{S}_{8}$ molecules; near and above the threshold temperature, these cyclic units tend to open and to chain. A dynamical equilibrium thus establishes among closed rings, open rings and chains of different length; large chains can eventually close, becoming polymer rings, while unstable linear allotropes of sulphur have also been detected [11,12] in small amounts. The phenomenon is fully reversible and controlled by thermodynamic parameters, mainly by the temperature.

The experimental determination of the mass fraction of polymer in liquid sulphur has been performed using chemical dissolution methods [13] or Raman spectroscopy [14], while estimates of the average chain length have been produced by means of ESR [15] or from magnetic susceptibility measurements [16]. A deeper knowledge of the chain length distribution has been so far prevented by the difficulty in discriminating experimental contributions from sulphur chains of different lengths.

During the $\lambda$ transition, the polymer mass fraction grows up to 0.55 , while the average chain length is almost always above $10^{3}$ atoms and can be as large as $10^{6}$. While it is well established in general [17] that an increase of shear viscosity can stem from variations in polymer content and chain lenght, a detailed picture of the dynamics in liquid sulphur and its evolution across the $\lambda$ transition is still missing. 


\section{Experimental details}

Sulphur of $99.999 \%$ purity was purchased from Sigma-Aldrich chemicals and physically purified by boiling under low pressure ( 2 mbar) dry nitrogen in a glass test tube (inner diameter $10 \mathrm{~mm}$ ). The tube was then flame sealed and inserted in the copper sample holder of an experimental chamber. Care was taken to avoid overheating and contamination during preparation; the sample was kept skew during the solidification, to deposit sulphur on the tube wells and prevent explosion of the tube due to thermal expansion of the polycrystalline solid at melting.

During the measurements the temperature was monitored through a $100 \Omega$ platinum resistance sensor and controlled by a PID feedback loop. Using this setup we were able to reduce thermal fluctuations within $5 \cdot 10^{-2} \mathrm{~K}$ around the selected temperature, in the range between room temperature and about $570 \mathrm{~K}$. Two optical paths were selectable, allowing back scattering and a $90^{\circ}$ scattering configuration.

[Insert figure 1 about here]

The light source used was a Coherent Innova $300 \mathrm{Ar}^{+}$laser, tuned on a single line of the $514.5 \mathrm{~nm}$ mode, vertically polarized with respect to the scattering plane; the light scattered from the sample was analysed by means of a Sandercock type $3+3$ pass tandem interferometer, with a typical contrast higher than $10^{9}$ and a finesse of $\sim 100$. 
During the $\lambda$ transition, power absorption greatly increases in the higher part of the optical spectrum [4]: a very low incident light intensity must be adopted in order to avoid local heating of the sample. We performed tests to check the power dependence of the gathered spectra; neutral density filter were then employed to keep the effective power on the sample below $0.7 \mathrm{~mW}$. This value of incident power was found low enough to give no sensible power dependence of results. The back scattering measurements were taken without any polarization analyser (VU configuration); some of the measurements carried out in $90^{\circ}$ scattering geometry were performed inserting a dichroic sheet polarizer between the sample and the interferometer, to select the horizontally polarized scattered light contribution (VH configuration).

\section{Results and discussion}

Brillouin light scattering spectra were collected in back scattering geometry at temperatures between the melting point and $530 \mathrm{~K}$; a subset of the data is shown in figure 1 . In all the spectra, the Brillouin doublet due to longitudinal modes propagating in the fluid is well visible at frequencies around $10 \mathrm{GHz}$. After each change in temperature, various measurements were taken in succession and compared each other to ensure full chemical and thermal equilibrium had been reached in the sample.

[Insert figure 2 about here]

The characteristic frequency $\Omega$ and half width $\Gamma$ of the longitudinal acoustic modes was determined by fitting the Brillouin peaks region to a damped harmonic oscillator (DHO) model function :

$$
I(q, \omega)=\frac{1}{\pi} \frac{\Gamma \Omega^{2}}{\left(\omega^{2}-\Omega^{2}\right)^{2}+(\Gamma \omega)^{2}}
$$

convoluted with the instrumental function. Exchanged momentum $(q)$ values were calculated keeping into account the thermal variation of index of refraction [3] through the relationship $q=$ $2 \mathrm{nK}_{i} \sin \theta / 2$, where $\mathrm{K}_{\mathrm{i}}$ is the incident light wave number $\mathrm{K}_{\mathrm{i}}=2 \pi / \lambda$. The same values were used to get estimates of real part (M') and imaginary part (M') of the longitudinal elastic modulus M, through the relations :

$$
\begin{aligned}
& M^{\prime}(\Omega)=\frac{\Omega^{2} \rho}{q^{2}} \\
& M^{\prime \prime}(\Omega)=\frac{\Gamma \Omega \rho}{q^{2}}
\end{aligned}
$$

where the mass density $\rho$ is from ref. [5]. The longitudinal sound speed $c$ in the GHz frequency region can be calculated from $M^{\prime}$ values using the relation $M^{\prime}=c^{2} \cdot \rho$. The values obtained are shown 
in figure 2 (top graph), compared with estimates of the same physical observable at ultrasonic frequencies [6-9] and with the limiting high frequency ( $\mathrm{THz}$ region) values recently obtained by means of IXS [18].

A BLS investigation on liquid sulphur was performed in the past [19], using He-Ne laser light and a spectroscopic instrumentation quite similar to our one. In this work, the purification of the sample was very accurate and the red light source was chosen to avoid local heating effects. Nonetheless, the authors adopted a complex model for data analysis, obtaining an anomalous scatter of the fitting parameters and being, for their own admission, unable of drawing significant conclusions about the physical interpretation of the parameters. Moreover, since the exchanged momentum is different from our one, a comparison with our results would be cumbersome and would take us far from the main topic of this work. The present work investigates sulphur in a wider temperature range than [19], obtaining a smoother and clearer dataset, which allows us to draw specific conclusions.

A strong relaxation is clearly present in longitudinal modulus between the $\mathrm{GHz}$ frequency range and the $\mathrm{THz}$ range, at temperatures both below and above the $\lambda$ transition threshold. Such a big variation can be ascribed to the main structural relaxation: its substantial independence from temperature indicates a weak correlation between the big change in viscosity across the $\lambda$ transition and the main structural relaxation. This thesis is confirmed also by the behaviour of the imaginary part of the modulus (figure 2, bottom), proportional to acoustic absorption, which decreases exactly in the temperature region of larger viscosity, where we should expect a slowing down of the main structural relaxation time and an increase in sound absorption. On this basis, we believe also that the low frequency tail of the structural relaxation is responsible for the variation in sound speed between the ultrasonic regime and the Brillouin frequency range.

During the measurements, we also performed a series of $90^{\circ}$ depolarized ( $\mathrm{VH}$ configuration) scattering observation in the highest viscosity temperature range, looking for signs of transverse modes propagating in the sample but, also in this case, no evidence of a structural slowing down was found.

The single relaxation model is evidently inadequate to describe the dynamics of liquid sulphur during the $\lambda$ transition. The main structural relaxation time appears unchanged by the transition, so an additional relaxation must be hypothesized [18], contributing to viscosity as an additional term in the Maxwell relation :

$$
\eta=\tau_{s}\left(G_{\infty}-G_{\infty 1}\right)+\tau_{r} G_{\infty 1}
$$

The relaxation time $\tau_{\mathrm{r}}$ and unrelaxed shear modulus $\mathrm{G}_{\infty 1}$ of this additional relaxation can now be roughly guessed. Rheometric measurements on quick quenched semi polymeric sulphur samples [20] indicate (low temperature trend) a value of $\mathrm{G}_{\infty}$ of about $10^{10} \mathrm{~Pa}$, while suggesting (high 
temperature trend) a superior limit for $\mathrm{G}_{\infty 1}$ of about $10^{6} \mathrm{~Pa}$. Assuming these values, we can consider $G_{\infty 1}$ to be very small when compared to $G_{\infty}$. If the main structural relaxation time $\tau_{\mathrm{s}}$ remains in the ps scale during the $\lambda$ transition, the first contribution to viscosity will be always in the order of $10^{-2} \mathrm{~Pa} \cdot \mathrm{s}$ and the large part of the viscosity in the same temperature region must be provided by the second term. Given the value of $\mathrm{G}_{\infty 1}, \tau_{\mathrm{r}}$ should be at least larger than $10^{-4} \mathrm{~s}$ to obtain a viscosity of $100 \mathrm{~Pa} \cdot \mathrm{s}$ during the transition [18].

The existence of very low frequency relaxations is typical of concentrated solutions of linear uncross linked polymers [17] and is due to entanglement coupling between chains in the melt. The onset of an entanglement related relaxation at low frequencies usually leads to rubber-like elastic behaviour and would be sound for sulphur, given the high average weight of the polymer chains produced in the region of larger increase of the viscosity.

\section{Conclusions}

Brillouin light scattering measurements were performed in liquid sulphur in the $\lambda$ transition region. The experimental results confirm the hypothesis [18] that the large increase in shear viscosity during the transition does not correspond to a slowing down of the main structural relaxation, but rather to the onset of an additional very low frequency relaxation, to be found below $10 \mathrm{kHz}$. Such a feature should be related to the increasing polymer mass fraction in the melt, and specifically to entanglement coupling between sulphur polymer chains. Ultrasonic works in literature were all performed at frequencies higher than $500 \mathrm{kHz}$, thus being unable to reveal the existence of this relaxation, exploring partially relaxed regimes and finding apparent violations of hydrodynamic predictions [9]. An experimental effort is currently in progress, in collaboration with dr. Tullio Scopigno (CRS-SOFT Rome, IT) and dr. Spyros Yannopoulos (FORTH/ICE-HT Patras, GR), to directly observe the timescale where the low frequency relaxation should be located. 


\section{References}

[1] R.F. Bacon, and R. Fanelli, J. Am. Chem. Soc. 65, 639 (1943).

[2] E.D. West, J. Am. Chem. Soc. 81, 29 (1959).

[3] A. Donaldson and A.D. Caplin, 1985, Phyl. Mag. B 52, n. 2, 185.

[4] S. Hosokawa, T. Matsuoka and K. Tamura, J. Phys. Cond. Matt. 6, 5273 (1994).

[5] A.M. Kellas, J. Chem. Soc. 113, 903 (1918).

[6] M.B. Gitis and I.G. Mikhailov, Sov. Phys. Acoust. 13, no. 2, 251 (1967).

[7] D.L. Timrot, M.A. Sredniskaya and T.D. Chkhikvadze, Dokl. Akad. Nauk. SSSR 279, 617 (1984).

[8] V.F. Kozhevnikov, J.M. Viner and P.C. Taylor, Phys. Rev. B 64, 214109 (2001).

[9] V.F. Kozhevnikov, W.B. Payne, J.K. Olson, C.L. McDonald and C.E. Inglefield, J. Chem. Phys. 121, no. 15, 7379 (2004).

[10] S.C. Greer, Adv. Chem. Phys. XCIV, 261 (1996).

[11] R. Steudel, Top. Curr. Chem. 230, 81 (2003).

[12] R. Steudel, Top. Curr. Chem. 231, 31 (2003).

[13] J.C. Koh and W. Klement Jr., J. Phys. Chem. 74, 4280 (1970).

[14] A.G. Kalampounias, K.S. Andrikopoulos and S.N. Yannopoulos, 2003, J. Chem. Phys. 118, n. 18,8460 (2003).

[15] D.M. Gardner and G.K. Fraenkel, J. Am. Chem. Soc. 78, 3279 (1956).

[16] J.A. Poulis and W. Derbyshire, Trans. Faraday Soc. 59, 559 (1963).

[17] J.D. Ferry, Viscoelastic properties of polymers (John Wiley \& Sons, New York, 1980).

[18] G. Monaco, L. Crapanzano, R. Bellissent, W. Crichton, D. Fioretto, M. Mezouar, F. Scarponi, and R. Verbeni, Phys. Rev. Lett. 95, 255502 (2005).

[19] A.D. Alvarenga, M. Grimsditch, S. Susman and S.C. Rowland, J. Phys. Chem. 100, 11456 (1996).

[20] A.V. Tobolsky, W. MacKnight, R.B. Beevers and V.D. Gupta, 1980, Polymer 4, 423 (1980). 


\section{Figure captions}

\section{Figure.1 :}

Brillouin light scattering spectra taken in back scattering configuration at various temperatures. Original points have been stacked multiplying for an arbitrary factor to allow easier comparison of spectral features.

\section{Figure.2 :}

Results for the real part of the longitudinal elastic modulus in liquid sulphur from BLS measurements are reported in the top graph, compared with literature data from recent inelastic Xray scattering measurements [18] and various ultrasonic works in literature [6-9]. The imaginary part of the longitudinal elastic modulus is shown in the bottom graph. 


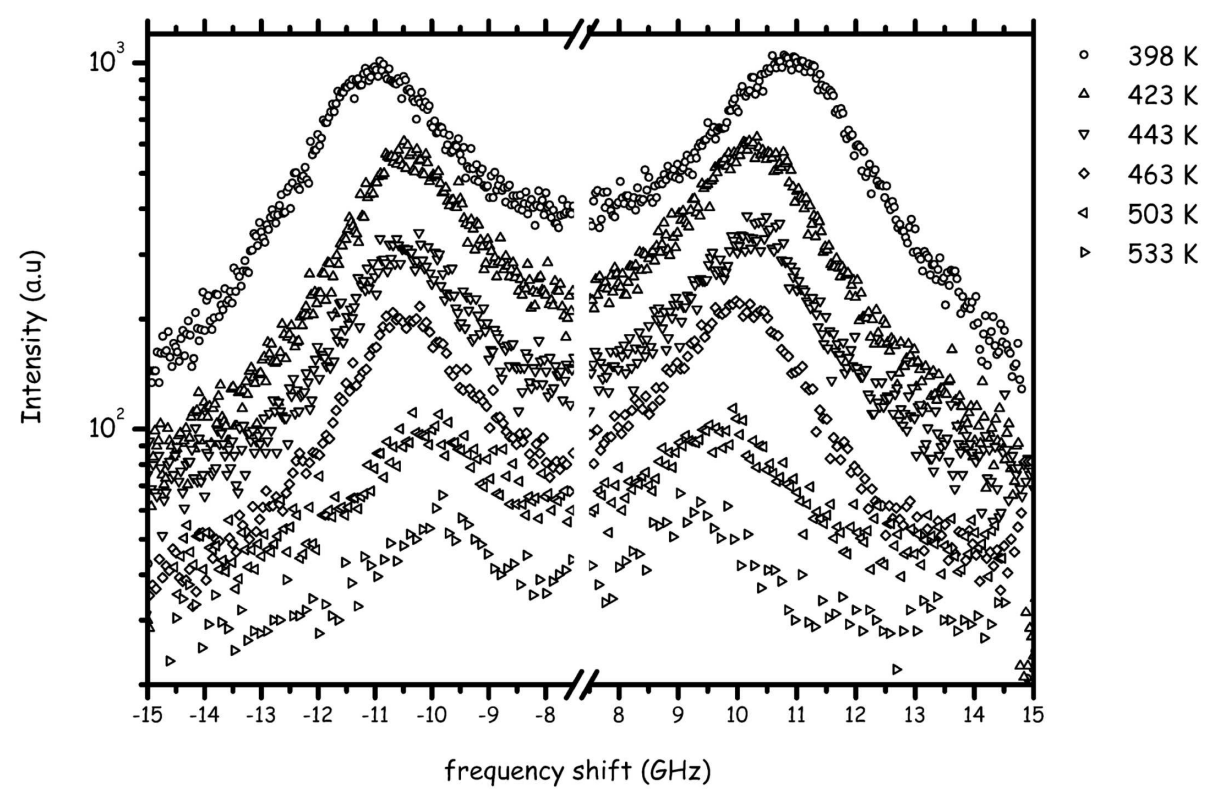

Figure 1

$149 \times 104 \mathrm{~mm}(400 \times 400 \mathrm{DPI})$ 


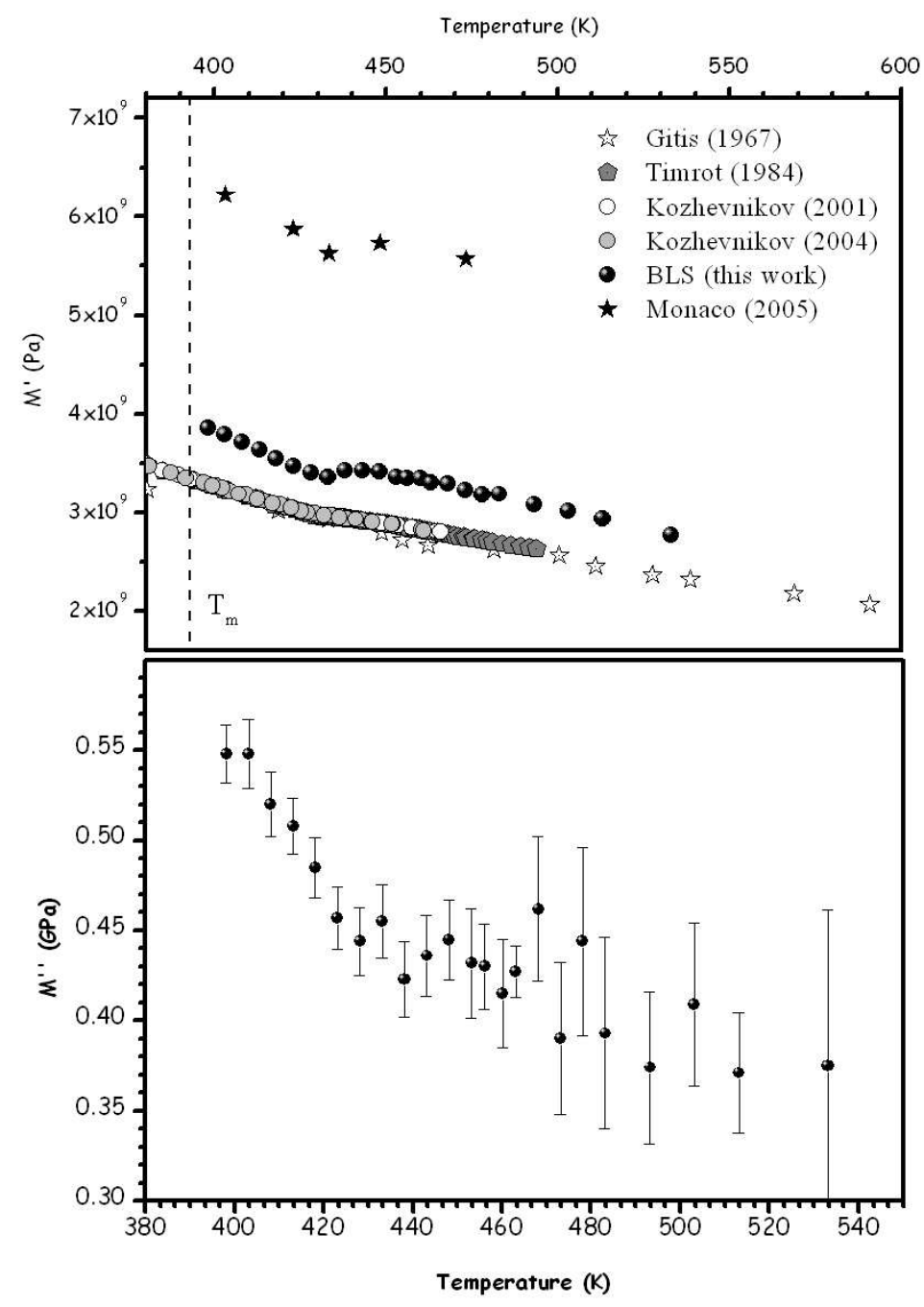

Figure 2 $402 \times 463 \mathrm{~mm}(72 \times 72 \mathrm{DPI})$ 


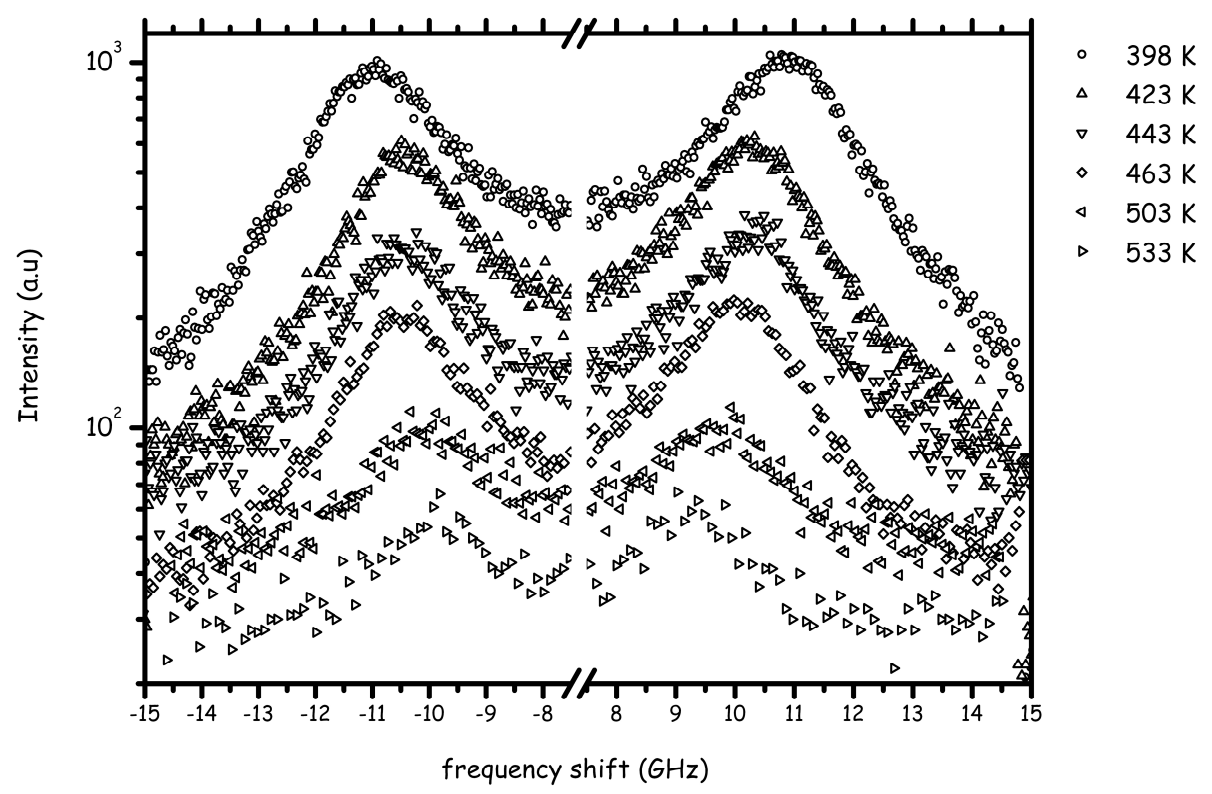




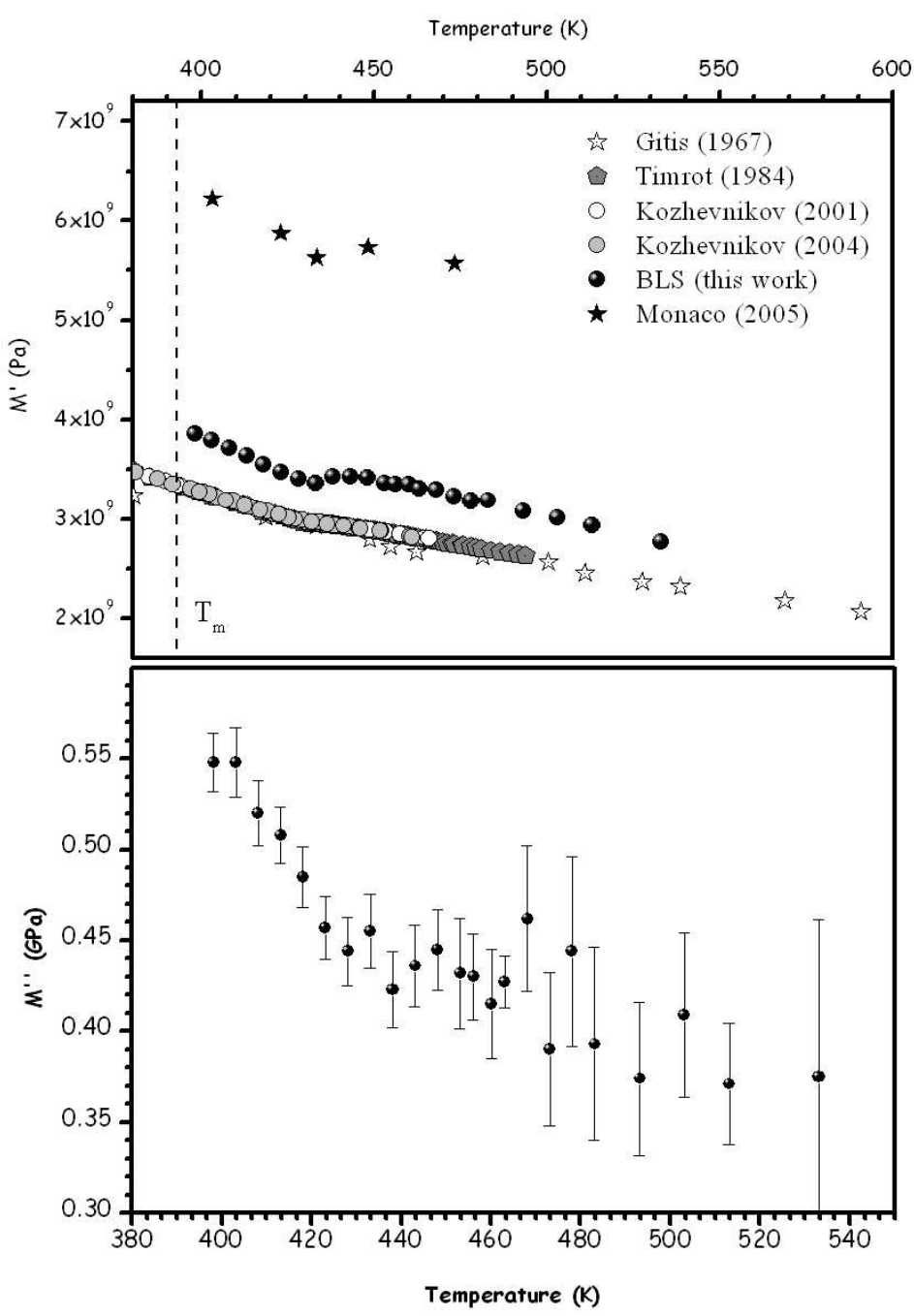

http://mc.manuscriptcentral.com/pm-pml 